\begin{tabular}{|c|c|c|c|c|c|c|}
\hline \multirow{4}{*}{ Impact Factor: } & ISRA (India) & $=3.117$ & SIS (USA) & $=0.912$ & ICV (Poland) & $=6.630$ \\
\hline & ISI (Dubai, UAE & $=\mathbf{0 . 8 2 9}$ & РИНЦ (Russia & $=0.156$ & PIF (India) & $=1.940$ \\
\hline & GIF (Australia) & $=0.564$ & ESJI (KZ) & $=8.716$ & IBI (India) & $=4.260$ \\
\hline & JIF & $=1.500$ & SJIF (Morocco & $=5.667$ & OAJI (USA) & $=0.350$ \\
\hline
\end{tabular}

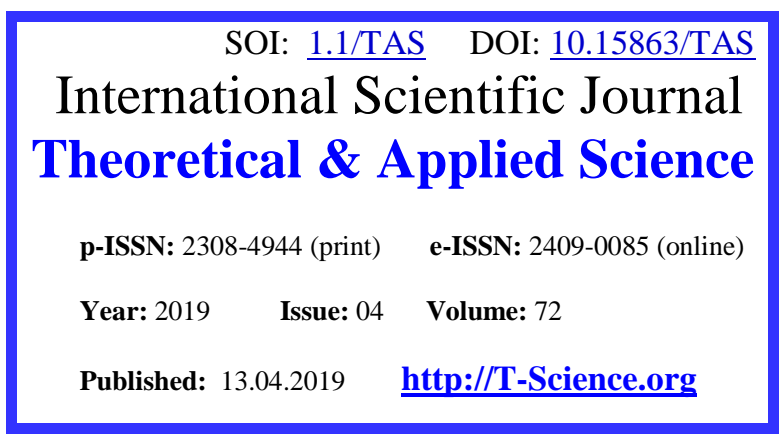

SECTION 11. Biology. Ecology. Veterinary.
QR - Issue

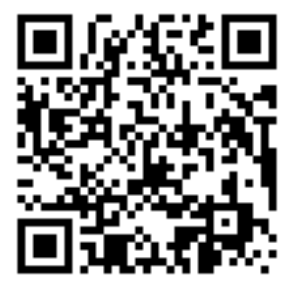

QR - Article

\title{
ALLOPATHIC EFFECTS OF THE LICHEN BIOMASS ON THE RUDERAL PLANTS SEEDLINGS FROM BRASSICAEAE FAMILY
}

Abstract: The results of an in vitro study of the lichen Cladonia arbuscula biomass influence on seed germination and seedlings initial growth of two ruderal species from the Brassicaceae family - Lepidium ruderale and Berteroa incana are presented in the paper. Data on the relationship between the amount of lichen biomass and the severity of its allelopathic effects on vascular plants are presented.

Key words: Allelopathy, lichen, biomass, ruderal plants, germination energy, germination, primary root, primary shoot.

Language: Russian

Citation: Khramchankova, V. M. (2019). Allopathic effects of the lichen biomass on the ruderal plants seedlings from brassicaeae family. ISJ Theoretical \& Applied Science, 04 (72), 109-115.

Soi: http://s-o-i.org/1.1/TAS-04-72-18 Doi: crossef https://dx.doi.org/10.15863/TAS.2019.04.72.18

\section{АЛЛЕЛОПАТИЧЕСКОЕ ДЕЙСТВИЕ БИОМАССЫ ЛИШАЙНИКА НА ВСХОДЫ РУДЕРАЛЬНЫХ РАСТЕНИЙ СЕМЕЙСТВА КАПУСТНЫЕ}

Аннотация: В работе изложены результаты in vitro исследования аллелопатического влияния биомассы лишайника кладония лесная на всхожесть семян и первичный рост проростков двух видов рудеральных растений семейства капустные - клоповника мусорного и икотника серого. Приводятся данные о зависимости силь аллелопатического действия лишайника на высшие растения от количества внесенной лихеномассы.

Ключевые слова: Аллелопатия, лишайник, биомасса, рудеральные растения, энергия прорастания, всхожесть, первичный корень, первичный побег.

\section{Введение}

Феномен взаимного влияния растений и относимых к ним организмов известен с глубокой древности. Практическое значение аллелопатии вплоть до середины прошлого столетия сводилось к набору довольно слабо описанных фактов, каковые на основании эмпирического опыта поколений имели в виду земледельцы, возделывая определенные культуры. Упоминания о пагубном действии одних растений на другие при их совместном произрастании встречаются у Теофраста (372 - 285 гг. до н.э.); в средневековых китайских трактатах; трудах энциклопедистов Нового времени (О.П. Декандоль и др.); работах европейских ученых периода становления физиологии растений как науки (конец XVIII начало $\mathrm{XX}$ вв.). Термин «аллелопатия» (от греческих allelon - взаимно и pathos - страдание) ввел в науку Г. Молиш (1856 - 1937) для обозначения явления выделения одним видом растений в окружающую среду веществ, подавляющих рост других видов растений, разделяющих то же место обитания [1].

Э. Райс [2] определяет аллелопатию как стимулирующее и/или ингибирующее действие одного растения на другое, включающее участие микроорганизмов, обитающих в том же фитоценозе. Всемирный аллелопатический конгресс 1996 г. определил аллеллопатию как «любой процесс с участием вторичных метаболитов, производимых растениями, водорослями, бактериями и грибами, влияющих на рост и развитие сельскохозяйственных культур и биологических систем». В настоящее время под 


\begin{tabular}{|c|c|c|c|c|c|c|}
\hline \multirow{4}{*}{ Impact Factor: } & ISRA (India) & $=3.117$ & SIS (USA) & $=0.912$ & ICV (Poland) & $=6.630$ \\
\hline & ISI (Dubai, UAE & $=\mathbf{0 . 8 2 9}$ & РИНЦ (Russia & $=0.156$ & PIF (India) & $=1.940$ \\
\hline & GIF (Australia) & $=0.564$ & ESJI (KZ) & $=8.716$ & IBI (India) & $=4.260$ \\
\hline & JIF & $=1.500$ & SJIF (Morocco & $=5.667$ & OAJI (USA) & $=0.350$ \\
\hline
\end{tabular}

аллелопатией понимают свойство одних организмов выделять химические соединения, которые тормозят или подавляют развитие других; а также как отрицательные, так и положительные взаимодействия между растениями в фитоценозах.

Ответственными за аллелопатию назначены четыре группы веществ [3, 4]:

- антибиотики

(продуцируются микроорганизмами и служат для подавления других микроорганизмов);

- маразмины (продукты обмена микроорганизмов и грибов, подавляющие жизнедеятельность высших растений);

- фитонциды (образуемые высшими растениями биологически активные вещества, подавляющие рост и развитие микроорганизмов);

- колины (выделяемые высшими растениями вещества, подавляющие другие высшие растения).

Очевидна «назначенность» и тривиальность подобной классификации аллелопатических веществ: каждое из определений не однозначно; каждая группа веществ включает множество соединений различных классов; каждая из групп соединений имеет специфические и общие для всех механизмы действия; наконец, нет дифференциации на прижизненные выделения организмов и продукты естественной деградации их посмертной совокупности веществ.

Аллелопатические соединения выделяются в окружающую среду в виде летучих веществ, экссудатов вегетативных и генеративных органов растений, различного рода выщелачиваний и др. Сюда же, очевидно, следует отнести продукты микробных и ферментативных трансформаций и деструкции как пожнивных остатков в агроценозах, так и естественного опада в других фитоценозах.

В настоящее время научные исследования и разработки в области аллелопатии крайне актуальны не только для биоэкологии, но также для сельского и лесного хозяйства. Широкое внедрение в науку и практику физико-химических методов исследования в сочетании с традиционными общебиологическими подходами в обозримом будущем позволят решить ряд основных научных проблем и наметить пути практического использования явления аллелопатии.

К числу фундаментальных аспектов аллелопатических исследований можно отнести:

- определение явления аллелопатии в количественных категориях, а также более строгое понятийное выделение аллелопатии среди других типов взаимодействий организмов в фитоценозах;
- оценка роли аллелопатии как эволюционной стратегии выживания одних видов в условиях доминирования других;

- анализ путей синтеза аллелопатических соединений в организмах продуцентов, механизмов химической модификации этих соединений при попадании во внешнюю среду;

- поиск, выделение и идентификация новых аллелопатических соединений, широкий скриниг аллелопатической активности известных агентов и вновь обнаруженных;

- всестороннее изучение механизмов молекулярног, биохимического и физиологического действия аллелопатических соединений на растения: ингибирование или стимуляцию активности ферментов, синтез нуклеиновых кислот и белков, метаболизм липидов и органических кислот, проницаемость мембран, ультраструктуру клеток, их деление и дифференцировку, фотосинтез, дыхание, водный обмен и минеральное питание, гормониндуцированный рост;

- оценка вклада аллелопатии в регулирование численности и продуктивности растительных сообществ;

- разработка классификации аллелопатических соединений,

Прикладными областями учения об аллелопатии могут выступать:

- оценка возможностей использования встречающихся в природе аллелопатических соединений в качестве средства подавления роста и развития нежелательных для человека растений в виде контроля численности определенных видов растений без их уничтожения;

- биотехнология аллелопатических соединений и их «производителей»: такой подход может позволит снизить, или вообще отменить использование пестицидов в сельском хозяйстве.

Аллелопатические свойства лишайников в значительной степени декларированы: утверждения об их наличии базируются на огромном материале, описывающем состав $[5,6]$ и биологические свойства так называемых «лишайниковых веществ» [7-12]; и на существенно меньшем и довольно противоречивом массиве экспериментальных данных о наличии/отсутствии влияния лишайников на жизнедеятельность высших растений [13-19]. Весьма примечательным является обзор [13], систематизирующий современные взгляды на взаимоотношения лишайников и высших растений. В пользу наличия аллелопатических свойств у лишайников свидетельствуют работы, посвященные ингибирующему действию экстрактов из лишайников, а также выделенных из них вторичных метаболитов [3, 20-23]. 


\begin{tabular}{|c|c|c|c|c|c|c|}
\hline \multirow{4}{*}{ Impact Factor: } & ISRA (India) & $=3.117$ & SIS (USA) & $=0.912$ & ICV (Poland) & $=6.630$ \\
\hline & ISI (Dubai, UAE & $=\mathbf{0 . 8 2 9}$ & РИНЦ (Russia & $=0.156$ & PIF (India) & $=1.940$ \\
\hline & GIF (Australia) & $=0.564$ & ESJI (KZ) & $=8.716$ & IBI (India) & $=4.260$ \\
\hline & JIF & $=1.500$ & SJIF (Morocco & $=5.667$ & OAJI (USA) & $=0.350$ \\
\hline
\end{tabular}

Целью настоящего исследования является оценка аллелопатического действия измельченной биомассы лишайника на всхожесть и первичный рост двух видов сорных растений семейства капустные.

\section{Методы исследований}

Для исследования был выбран лишайник Cladonia arbuscula (Wallr.) Flot. (Syn. Cladonia sylvatica (L.) Hoffm.). (рис. 1 [24]), часто встречающийся на юго-востоке Беларуси $[25,26]$.

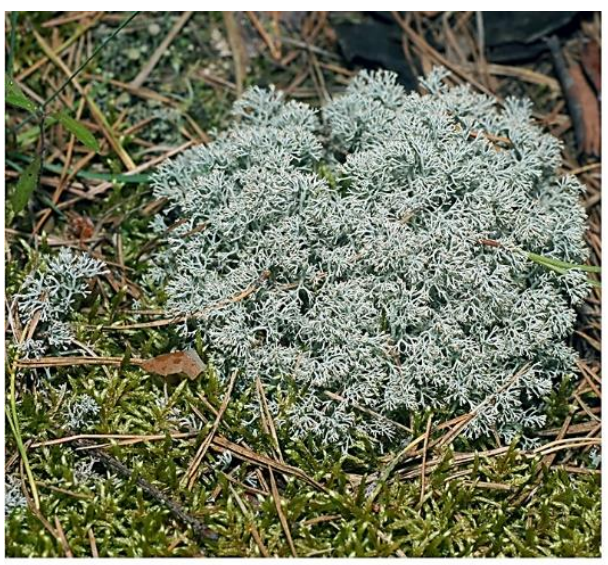

Cladonia arbuscula

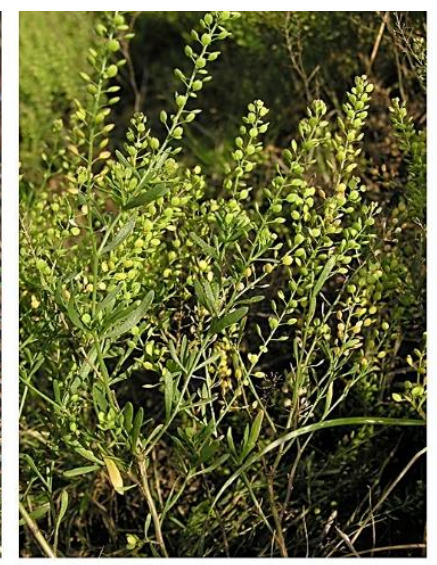

Lepidium ruderale

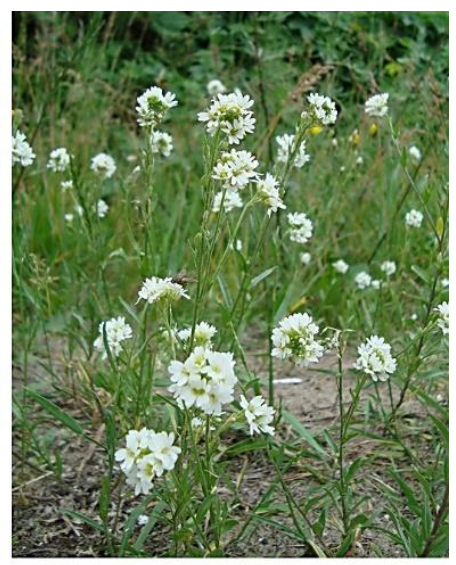

Berteroa incana

Рисунок 1 - Внешний вид объектов исследования [24]

Биомассу лишайника собирали в сухом приспевающем сосняке, очищали от опада, отбрасывали нижнюю часть подециев, сушили до воздушно-сухого состояния, измельчали. В качестве объекта исследования были выбраны типичные рудералы семейства капустные клоповник мусорный (Lepidium ruderale L.) и икотник серый (Berteroa incana DC.). Оба вида характеризуются крайне высокой семенной продуктивностью и всхожестью только что созревших семян. Семена рудеральных растений собирали в естественных условиях их обитания, высушивали при комнатной температуре, подвергали стратификации на протяжении 1 месяца, после чего определяли всхожесть. Партии семян, имеющие всхожесть не ниже $98 \%$ использовали в эксперименте.

Семена клоповника мусорного и икотника серого проращивали на свету в пластиковых контейнерах при температуре $22 \pm 2{ }^{\circ} \mathrm{C}$. На дно контейнера укладывали 3 слоя фильтровальной бумаги, на верхнем слое равномерно распределяли измельченную биомассу лишайника, в которую выкладывали семена сорных растений. Для каждого варианта опытов проращивали по 50 семян в пятикратной повторности, для увлажнения среды проращивания использовали смесь Кнопа, разведенную водой в соотношении 1:10. Навески биомассы лишайника составляли 0,$01 ; 0,03$ и 0,05 г на 1 см $^{2}$ ложа прорастания семян. Для контрольных опытов использовали аналогичные подложки из фильтровальной бумаги без нанесения биомассы лишайника.

Учеты всхожести, а также измерения длины главного зародышевого корня и длины первичного побега производили на $3,5,7,10$ и 15 е сутки. Энергию прорастания семян оценивали на 5-е сутки; всхожесть - на 10-е сутки. Полученные результаты обрабатывали с использованием стандартного программного продукта Статистика 7.0 .

\section{Результаты исследований}

Установлено аллелопатическое влияние биомассы лишайника кладония лесная на посевные качества семян рудеральных растений (рис. 2). 


\begin{tabular}{|c|c|c|c|c|c|c|}
\hline \multirow{4}{*}{ Impact Factor: } & ISRA (India) & $=\mathbf{3 . 1 1 7}$ & SIS (USA) & $=0.912$ & ICV (Poland) & $=6.630$ \\
\hline & ISI (Dubai, UAE & $=0.829$ & РИНЦ (Russia & $=0.156$ & PIF (India) & $=1.940$ \\
\hline & GIF (Australia) & $=0.564$ & ESJI (KZ) & $=8.716$ & IBI (India) & $=4.260$ \\
\hline & JIF & $=1.500$ & SJIF (Morocco & $=5.667$ & OAJI (USA) & $=0.350$ \\
\hline
\end{tabular}

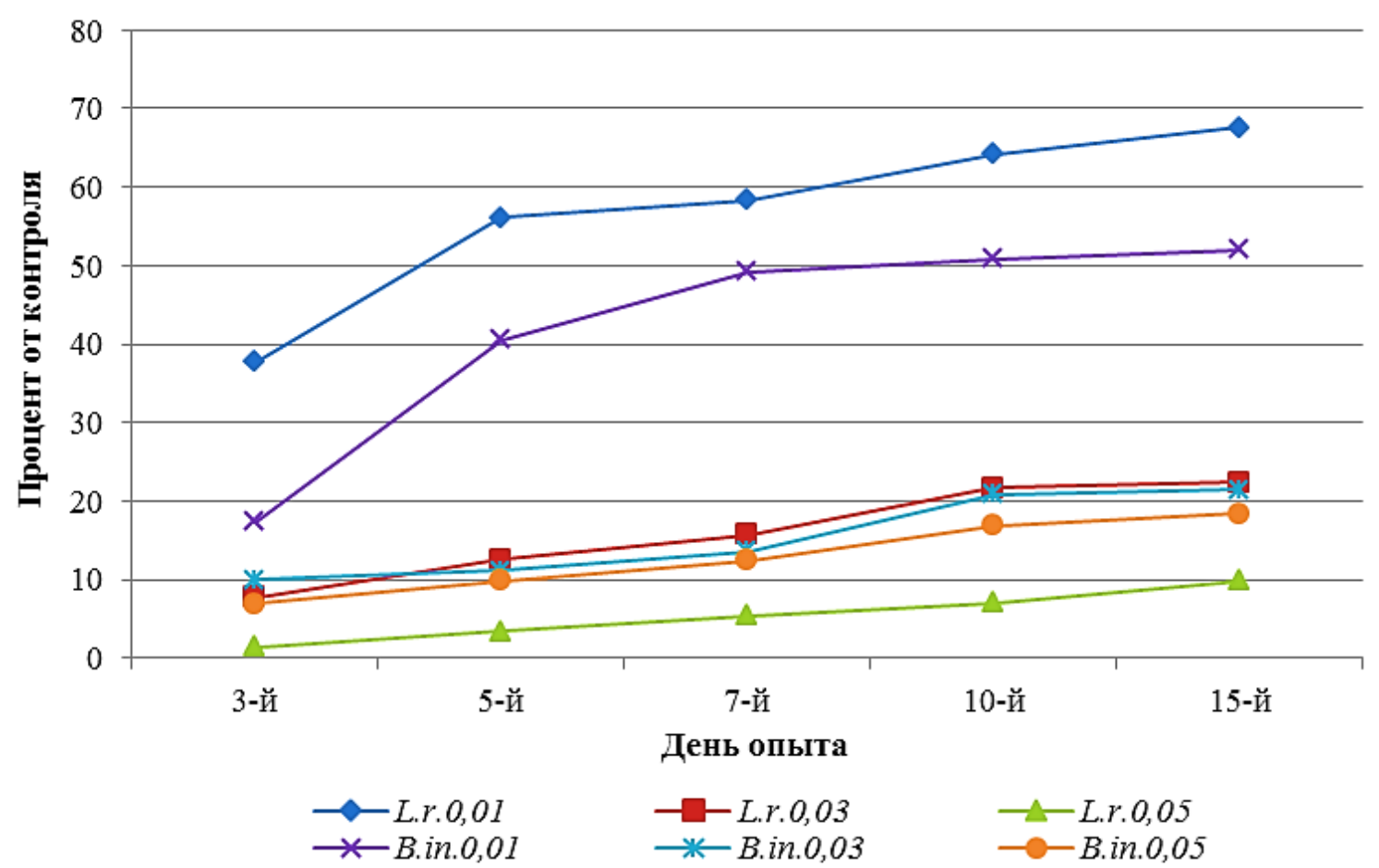

Рисунок 2 - Всхожесть семян клоповника мусорного (L.r.) и икотника серого (B.in.)

в присутствии биомассы лишайника на пятые - пятнадцатые сутки опыта.

0,$01 ; 0,03$ и 0,05 - количество биомассы лишайника на ложе прорастания семян, г/см².

Присутствие биомассы лишайника в

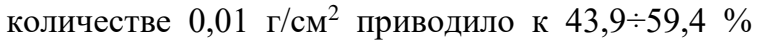
снижению энергии прорастания и к $35,8 \div 49,1 \%$ падению всхожести семян клоповника мусорного и икотника серо-зеленого. Увеличение количества биомассы лишайника на поверхности ложа прорастания вызывало подавление всхожести семян сорных растений, причем существенного значения не имело: вносилось лишайника 0,03

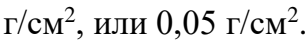

Следует отметить, что падение всхожести семян рудеральных растений в присутствии биомассы лишайника соответствует тезису о снижении численности нежелательных для человека видов растений без их уничтожения.

Таким образом, измельченная биомасса лишайника кладония лесная подавляет всхожесть семян сорных растений - клоповника мусорного и икотника серо-зеленого.

Корни, сорных растений, вынужденные прорастать в среде, насыщенной лишайниковыми веществами, сильно отставали в росте от контрольных экземпляров (рис. 3). 


\begin{tabular}{|c|c|c|c|c|c|c|}
\hline \multirow{4}{*}{ Impact Factor: } & ISRA (India) & $=\mathbf{3 . 1 1 7}$ & SIS (USA) & $=0.912$ & ICV (Poland) & $=6.630$ \\
\hline & ISI (Dubai, UAE & $=0.829$ & РИНЦ (Russia & $=0.156$ & PIF (India) & $=1.940$ \\
\hline & GIF (Australia) & $=0.564$ & ESJI (KZ) & $=8.716$ & IBI (India) & $=4.260$ \\
\hline & JIF & $=1.500$ & SJIF (Morocco & $=5.667$ & OAJI (USA) & $=0.350$ \\
\hline
\end{tabular}

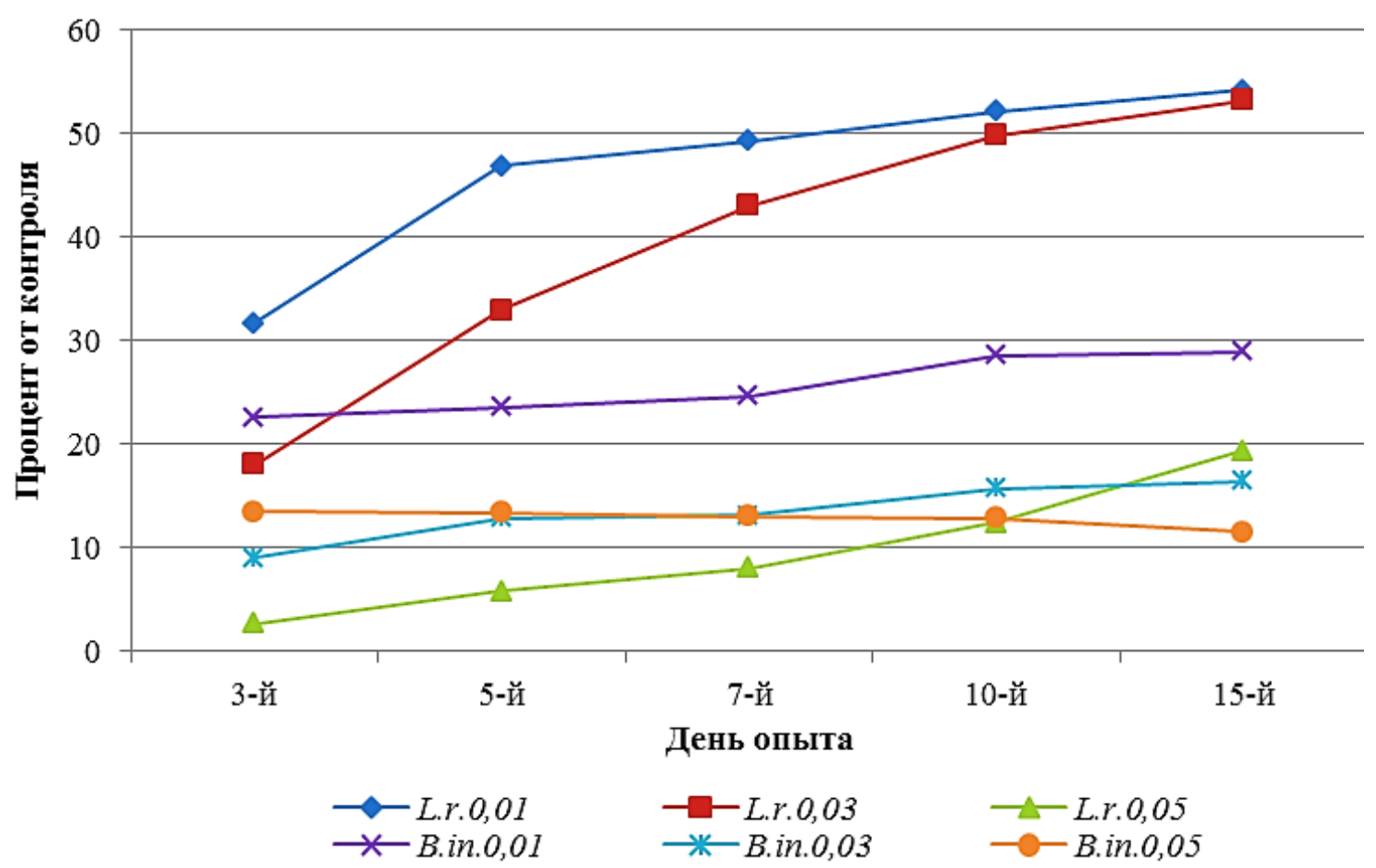

Рисунок 3 - Длина корней всходов клоповника мусорного (L.r.) и икотника серого (B.in.) в присутствии биомассы лишайника на пятые - пятнадцатые сутки опыта.

0,01; 0,03 и 0,05 - количество биомассы лишайника на ложе прорастания семян, г/см²

Отставание составило 53,2 $\div 74,4 \%$ при содержании биомассы лишайника 0,01 г/см²; до 90,3 \% - при содержании биомассы лишайника

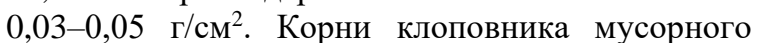
угнетались несколько меньше, чем корни икотника серо-зеленого.

O механизме подавляющего действия биомассы лишайника на рост корней высших растений можно судить по следующим данным. Ключевым вторичным метаболитом лишайника Cladonia arbuscula является усниновая кислота [27]. Это соединение - дибензофуран по химической природе [5] - в присутствии катионов первой аналитической группы, входящих в состав увлажняющего среду прорастания раствора (разбавленная смесь Кнопа) способно образовывать растворимые в воде соли уснинаты, биологическая активность которых хорошо описана в $[3,23]$. С другой стороны, из работы [28] следует, что соединения, переходящие в водный раствор из биомассы лишайников, представляют собой однозамещенные монофенолы, чья токсичность для растений общеизвестна.

Реакция первичных побегов сорных растений на присутствие измельченной биомассы лишайника в среде прорастания хорошо укладывается в современные представления о реализации фитостресса (рис. 4). 


\begin{tabular}{|c|c|c|c|c|c|c|}
\hline \multirow{4}{*}{ Impact Factor: } & ISRA (India) & $=\mathbf{3 . 1 1 7}$ & SIS (USA) & $=0.912$ & ICV (Poland) & $=6.630$ \\
\hline & ISI (Dubai, UAE & $=0.829$ & РИНЦ (Russia & $=0.156$ & PIF (India) & $=1.940$ \\
\hline & GIF (Australia) & $=0.564$ & ESJI (KZ) & $=8.716$ & IBI (India) & $=4.260$ \\
\hline & JIF & $=1.500$ & SJIF (Morocco & $=5.667$ & OAJI (USA) & $=0.350$ \\
\hline
\end{tabular}

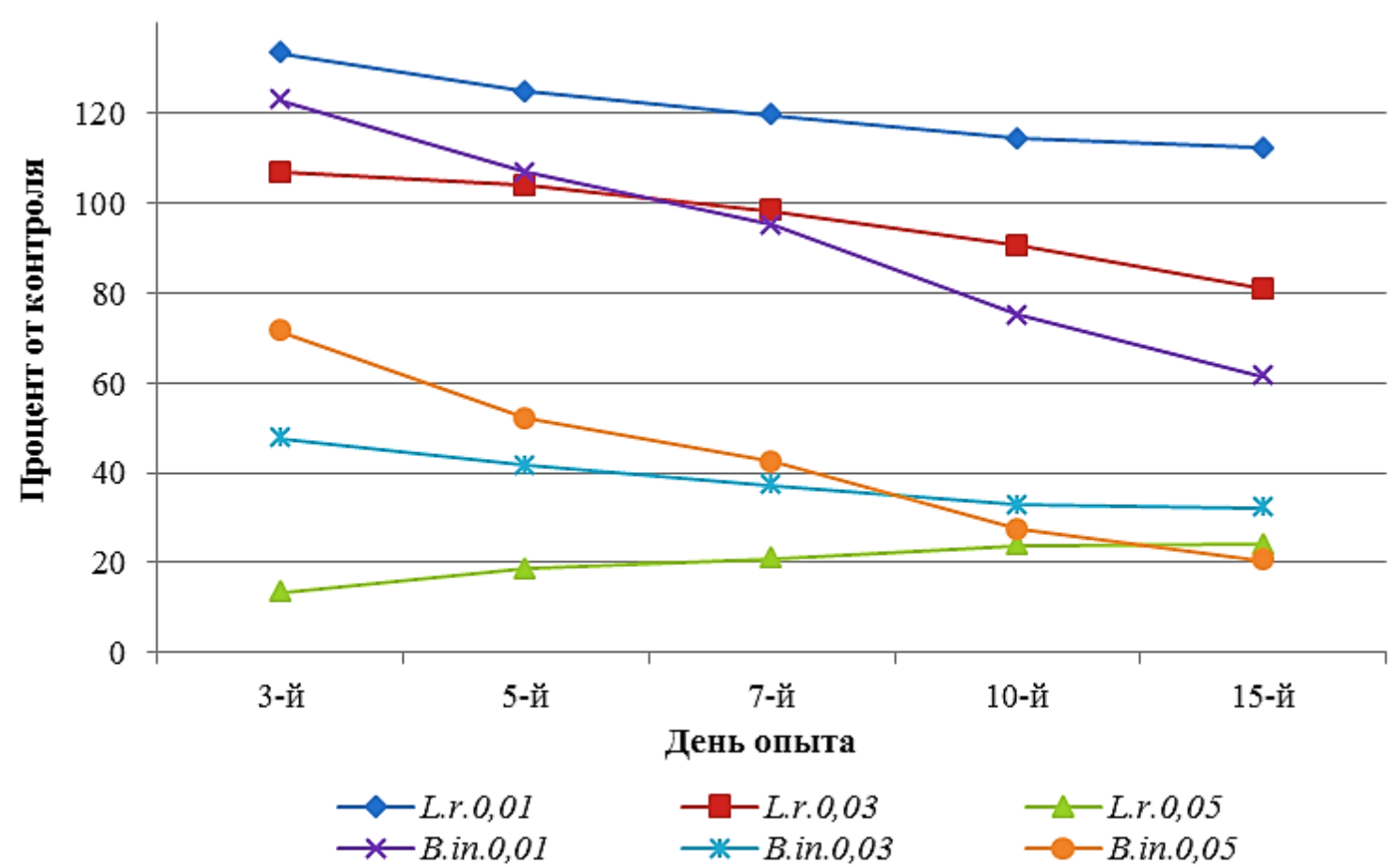

Рисунок 4 - Длина первичного побега всходов клоповника мусорного (L.r.) и икотника серого (B.in.) в присутствии биомассы лишайника на пятые - пятнадцатые сутки опыта. 0,$01 ; 0,03$ и 0,05 - количество биомассы лишайника на ложе прорастания семян, г/с $\mathrm{cm}^{2}$.

Предпороговые концентрации биомассы

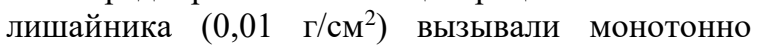
уменьшающуюся стимуляцию роста побегов (на 22,9-33,3 \% выше контрольных значений). Более высокие концентрации биомассы лишайника $(0,03$ $\left.\Gamma / \mathrm{cm}^{2}\right)$ видоспецифично подавляли рост побегов. Самые высокие концентрации лишайника без подавляли рост побегов всякой видоспецифичности.

\section{Заключение.}

Установлено аллелопатическое действие измельченной биомассы лишайника кладония лесная на рудеральные растения клоповник мусорный и икотник серый. Снижение энергии прорастания семян и всхожести, угнетение роста корней и побегов зависит от количества внесенной в среду прорастания биомассы лишайника.

\section{References:}

1. Willis, R. J. (2007). The History of Allelopathy. (p.316). New York: Springer.

2. Rice, E. L. (1984). Allelopathy. Physiological Ecology. (p.424). Orlando, FL: Academic Press.

3. Macias, F., Galindo, J., \& Molinillo, J. (2004). Allelopathy: chemistry and mode of action of allelochemicals. (p.372). CRC Press.

4. Reigosa, M. J., Pedrol, N., \& González L. (2006). Allelopathy: A Physiological Process with Ecological Implications. (p.638). Springer Science \& Business Media.
5. Huneck S., \& Yoshimura, I. (1996). Identification of lichen substances. (p.493). Berlin, Heidelberg.

6. Elix, J. A. (2014). A Catalogue of Standardized Thin Layer Chromatographic Data and Biosynthetic Relationships for Lichen Substances. (p.330). Australian National University, Canberra.

7. Boustie, J., \& Grube, M. (2005). Lichens - a promising source of bioactive secondary 


\begin{tabular}{|c|c|c|c|c|c|c|}
\hline \multirow{4}{*}{ Impact Factor: } & ISRA (India) & $=\mathbf{3 . 1 1 7}$ & SIS (USA) & $=0.912$ & ICV (Poland) & $=6.630$ \\
\hline & ISI (Dubai, UAE & $=0.829$ & РИНЦ (Russia & $=0.156$ & PIF (India) & $=1.940$ \\
\hline & GIF (Australia) & $=0.564$ & ESJI (KZ) & $=8.716$ & IBI (India) & $=4.260$ \\
\hline & JIF & $=1.500$ & SJIF (Morocco & $=5.667$ & OAJI (USA) & $=0.350$ \\
\hline
\end{tabular}

metabolites. Plant Genetic Resources, Vol. 3, №. 2: 273-287.

8. Shawuti, G., \& Abbas, A. (2007). Research progress on biological activities of lichens secondary metabolites. Food Sci. J. Vol. 28: 624-627.

9. Shukla, V., Joshi, G. P., \& Rawat, M. S. (2010). Lichens as a potential natural source of bioactive compounds: a review. Phytochemistry Reviews, Vol. 9, №. 2: 303-314.

10. Molnar, K., \& Farkas, E. (2010). Current results on biological activities of lichen secondary metabolites: a review. Z. Naturforsch. Vol. 65: 157-173.

11. Shrestha, G., \& Clair, L. L. S. (2013) Lichens: a promising source of antibiotic and anticancer drugs. Phytochemistry reviews, Vol. 12, №. 1: 229-244.

12. Bhattacharyya, S., et al. (2016). Lichen Secondary Metabolites and Its Biological Activity. American Journal of PharmTech Research. Vol. 6, № 6: 29-44.

13. Favero-Longo, S. E., \& Piervittori, R. (2010). Lichen-plant interactions. Journal of Plant Interactions, Vol. 5: 163-177.

14. Escudero, A., et al. (2007) Soil lichens have species-specific effects on the seedling emergence of three gypsophile plant species. Journal of arid environments, Vol. 70, № 1: 1828.

15. Deines, L., et al. (2007). Germination and seedling establishment of two annual grasses on lichen-dominated biological soil crusts. Plant and Soil. Vol. 295, № 1-2: 23-35.

16. Serpe, M. D., Zimmerman, S. J., Deines, L., \& Rosentreter, R. (2007). Seed water status and root tip characteristics of two annual grasses on lichen-dominated biological soil crusts. Plant and Soil. Vol. 303: 191-205.

17. Crittenden, P. D. (2000). Aspects of the ecology of mat-forming lichens. Rangifer, Vol. 20, № 23: $127-139$.
18. Kytöviita, M.-M., \& Stark, S. (2009). No allelopathic effect of the dominant forest-floor lichen Cladonia stellaris on pine seedlings. Functional Ecology, Vol. 23, 435-441.

19. Legaz, M. E., Monsó, M. A., \& Vicente, C. (2004) Harmful effects of epiphytic lichens on trees. Recent Res Devel Agron Hortic, Vol. 1: 110.

20. Yano-Melo, A. M., Vicente, C., \& Xavier- Filho, L. (1999). Allelopathic effect of the Cladonia verticillaris lichen extracts and fumarprotocetraric acid on the early growth of germinated seedlings in Allium cepa L. Tropical Bryology, Vol. 17: 133-139.

21. Peres, M. T. L. P., et al. (2009). Allelopathic Potential of Orsellinic Acid Derivatives. Braz. Arch. Biol. Technol. Vol. 52(4): 1019-1026.

22. Takahagi, T., et al. (2006). Inhibition of PSII in Atrazine-Tolerant Tobacco Cells by Barbatic Acid, a Lichen-Derived Depside. Bioscience, Biotechnology, and Biochemistry, Vol. 70(1): 266-268.

23. Latkowska, E., Lechowski, Z., Bialczyk, J., \& Pilarski, J. (2006). Photosynthesis and Water Relations in Tomato Plants Cultivated LongTerm in Media Containing (+)-Usnic Acid. $J$ Chem Ecol., Vol. 32: 2053-2066.

24. (2019). Planetarium [Electronic resource]. Retrieved April 4, 2019, from http://www. plantarium.ru

25. Tsurykau, A., \& Khramchankova, V. (2011). Lichens from Gomel region: a provisional checklist. Bot. Lith. Vol. 17 (4): 157-163.

26. Tsurykau, A. G. (2013). Lishajniki yugo-vostoka Belarusi (opyt lihenomonitoringa). (p.276). Gomel': GGU im. F. Skoriny.

27. (2009). The Lichens of Great Britain and Ireland. 2nd ed. 2009. In Smith C.W., et al. (Eds.). (p.700). London: British Lichen Society.

28. Zagoskina, N. V., et al. (2013). Water-Soluble Phenolic Compounds in Lichens. Microbiology, Vol. 82(4): 445-452. 